\title{
Perspective on skeletal health in inflammatory bowel disease
}

\author{
A. A. van Bodegraven ${ }^{1,2} \cdot$ N. Bravenboer ${ }^{3,4}$ (i) \\ Received: 2 November 2018 / Accepted: 14 November 2019 / Published online: 10 December 2019 \\ (C) The Author(s) 2019
}

\begin{abstract}
Osteopenia and osteoporosis are common features in inflammatory bowel disease (IBD), comprising both Crohn's disease and ulcerative colitis. Moreover, Crohn's disease is associated with increased fracture risk. The etiology of bone loss in IBD is multifactorial. It includes insufficient intake or absorption of calcium, vitamin D, and potassium; smoking; a low peak bone mass; a low body mass index; and decreased physical activity. In several studies, it has been shown that elevated concentrations of systemic and local pro-inflammatory cytokines, including tumor necrosis factor alpha (TNF- $\alpha$ ), interferon- $\gamma$ (IFN $\gamma$ ), interleukin (IL)-1 $\beta$, IL-4, IL-5, IL-6, IL-13, and IL-17, present in IBD patients are potentially detrimental for bone metabolism and may be responsible for bone loss and increased fracture risk. This perspective aims to review the current literature on the role of inflammatory factors in the pathophysiology of skeletal problems in IBD and to suggest potential treatment to improve bone health, based on a combination of evidence and clinical and pathophysiological reasoning.
\end{abstract}

Keywords Bone loss $\cdot$ Crohn's disease $\cdot$ Inflammatory bowel disease $\cdot$ Osteoporosis $\cdot$ Ulcerative colitus

\section{Introduction}

Inflammatory bowel disease (IBD) is characterized by a systemic, chronic, relapsing, and disbalanced inflammatory response, primarily originating from and expressed in the intestinal mucosa. IBD mainly comprises two distinct phenotypes: Crohn's disease and ulcerative colitis.

The incidence of IBD is worldwide rising with a north-tosouth gradient and appears to be introduced in the nonWestern world concurrent with industrialization, and the

N. Bravenboer

n.bravenboer@amsterdamumc.nl

A. A. van Bodegraven

a.vanbodegraven@zuyderland.nl

1 Department of Gastroenterology, Geriatrics, Internal and Intensive Care Medicine(Co-MIK), Zuyderland MC, Sittard-Geleen-Heerlen, Dr H van der Hoffplein 1, 6162 BG Geleen, Netherlands

2 Department of Gastroenterology, Amsterdam UMC, Location Vrije Universiteit, PO Box 7057, 1007 MB Amsterdam, Netherlands

3 Department of Clinical Chemistry, Research Institute Amsterdam Movement Sciences Amsterdam UMC, Location Vrije Universiteit, PO Box 7057, 1007 MB Amsterdam, Netherlands

4 Department of Internal Medicine, Endocrinology Section, Centre for Bone Quality LUMC, Albinusdreef 2, Leiden 2333 ZA, Netherlands accompanying dietary habits [1]. In the Netherlands, the annual incidence increased from 17.90 per 100,000 in 1991 to 40.36 per 100,000 in 2010 for IBD; from 5.84 per 100,000 to 17.49 per 100,000 for Crohn's disease; and from 11.67 per 100,000 to 21.47 per 100,000 for UC [2]. The onset typically occurs in the second and third decade of life, yet may start at any age. IBD is most commonly characterized by periods of active disease (relapse) and periods of remission (quiescent) [3]. IBD diagnosed in children and in adulthood is associated with osteopenia, osteoporosis, and fracture risk in several studies, both in Western [4-8] and in Asian [9] countries. The increased relative risk for osteoporosis or bone fractures when compared with a normal or general population is still a matter of debate. In a recent systematic review and meta-analysis, based on nine studies comparing IBD patients with general controls, the relative risk for global fracture was 1.38 (95\% CI 1.11-1.73). For vertebral fractures, odds ratio was 2.26 (95\% CI 1.04-4.90). In this paper, mean BMD and Zscores for IBD patients versus controls were decreased at all sites, and patients with IBD had an increased risk of fractures [10]. Vertebral fracture risk was also reported to be elevated in another meta-analysis considering IBD patients [11].

Skeletal health comprises a well-balanced bone metabolism necessary for growth and maintenance of bone tissue in order to function adequately in the skeleton. Healthy bone tissue protects from bone fracture due to low-energy, mechanical trauma. A biomarker of bone health is bone density, 
measured by dual-energy X-ray absorptiometry (DXA). Diagnosis of impaired bone health in IBD patients primarily depends on DXA measurements expressed in T-scores, sometimes Z-scores, whereas bone turnover markers in serum or urine are not being used in standard clinical practice. Similarly, bone biopsy and quantitative histopathology or CT scanning is unusual, but may be done in a research setting. Assessment of osteoporosis in younger patients has been extensively reviewed elsewhere [12].

As an indication of the burden caused by a diminished skeletal health in IBD patients, a prevalence of osteopenia from 32 to $36 \%$ and a prevalence of osteoporosis from 7 to $15 \%$ have been reported $[13,14]$. The estimated elevated excess risk for a fragility fracture in Crohn's disease patients compared with the general population was 30 to $40 \%$ more fractures $[15,16]$. An elevated risk of fractures has also been reported in patients suffering from ulcerative colitis, particularly at initial diagnosis [5]. Together with the data from an extensive review and metaanalysis comparing this burden with general controls, it seems advisable to identify patients with IBD who are at increased risk for osteoporosis in order to prevent fractures [10].

The etiology of bone loss in IBD is multifactorial (see Table 1). It includes the following: (I) variables primarily associated with skeletal health in general, such as potentially insufficient intake of calcium, vitamin D, magnesium, and potassium; smoking; decreased sun exposure; a low peak bone mass; a low body mass index; and decreased physical activity.

Additionally, an unbalanced diet and a dysbiotic intestinal microbiome, probably interacting, and partly uncharacterized and non-specific, may contribute to impaired bone health [17]. (II) IBD-associated factors a. due to IBD therapy, with detrimental effects of corticosteroids, still being (over) used in IBD patients, and beneficial effects of anti-TNF therapy,

b. due to disease-specific factors, such as sex hormone deficiency,

c. due to gastrointestinal damage as a result of ongoing inflammation and potentially leading to malabsorption and increased needs resulting from intestinal leakage. IBD, in particular Crohn's disease, may impair calcium and vitamin D absorption with (concurrent) osteomalacia as a direct consequence [18].

d. due to the inflammatory processes underlying IBD.

Most of the above-mentioned factors are - partly — uncharacteristic or atypical for IBD but occur concurrent with IBD.

Therapy is ideally primarily based on evidence-based medicine. Thus, convincing data from statistically well-powered trials in relevant populations are crucial. Unfortunately, these trials are sparse, particularly when considering robust clinical end points, i.e. reduction of bone fractures. Arguments for choice of treatment of impaired bone health are therefore also based on pathophysiological and clinical reasoning. To improve bone health, simple measures to change life style, diet, or medication may be helpful. Nutritional supplements, discontinuation of smoking, avoidance of (long-term) use of detrimental drugs, and increase of physical activity are well worth advising in general. Treatment specifically aimed at IBD-associated causes of decreased bone health is less well characterized. Rational, pathophysiology-based therapy needs further understanding of the (patho)physiological mechanisms underlying this IBD-associated osteoporosis. We therefore elaborate on
Table 1 Factors contributing to altered bone health in IBD patients

\begin{tabular}{|c|c|}
\hline \multicolumn{2}{|l|}{ General factors } \\
\hline \multicolumn{2}{|l|}{ Low intake of calcium } \\
\hline \multicolumn{2}{|l|}{ Decreased vitamin D concentrations } \\
\hline \multicolumn{2}{|c|}{ Low magnesium and potassium concentrations } \\
\hline \multicolumn{2}{|l|}{ Metabolic acidosis } \\
\hline \multicolumn{2}{|l|}{ Low peak bone mass } \\
\hline \multicolumn{2}{|l|}{ Low body mass index } \\
\hline \multicolumn{2}{|l|}{ Decreased physical activity } \\
\hline \multicolumn{2}{|l|}{ Smoking } \\
\hline \multicolumn{2}{|l|}{ Excessive alcohol consumption } \\
\hline \multicolumn{2}{|l|}{ IBD-associated factors } \\
\hline \multirow[t]{2}{*}{ IBD therapy } & Corticosteroids (detrimental) \\
\hline & Anti-TNF therapy (beneficial) \\
\hline \multirow[t]{2}{*}{ IBD-specific factors } & Sex hormone deficiency \\
\hline & Low body mass index/peak bone mass \\
\hline \multirow[t]{2}{*}{ Gastrointestinal damage } & Intestinal insufficiency (short bowel syndrome) \\
\hline & Intestinal leakage \\
\hline Inflammatory processes underlying IBD & Cytokine and other immunological networks in disbalance \\
\hline
\end{tabular}


the current knowledge regarding systemic inflammatory disease, such as in IBD, and the associated changes in bone health.

\section{Advances in the understanding of inflammation, inflammatory cytokines, and bone health}

In several studies, it has been shown that elevated concentrations of circulating pro-inflammatory cytokines including tumor necrosis factor alpha (TNF- $\alpha$ ), interleukin (IL)-1 $\beta$, IL-6, and IL-17 are present in IBD patients. Crohn's disease is reported to be associated with elevated concentrations of the Th1 pro-inflammatory cytokines IL-2, IL-17, interferon- $\gamma$ (IFN $\gamma$ ), and TNF- $\alpha$, while ulcerative colitis is associated with Th2-profile cytokines, such as IL-4, IL-5, and IL-13 [19]. Subsequently, it has been put forward that Th1, Th2, and Th17 cells are broadly involved in the pathogenesis of IBD through regulation of inflammatory cytokine networks. All of these pro-inflammatory factors are potentially detrimental for bone metabolism and may be responsible for bone loss and increased fracture risk. In most in vitro research, effects of a single cytokine on healthy osteoclasts have been analyzed. Additionally, it has been demonstrated that growth potential and differentiation capacity of primary bone cells harvested from patients with quiescent Crohn's disease are diminished. Yet, the response of bone cells from Crohn's disease patients to cytokines has been reported to be similar [20]. Cytokines such as TNF- $\alpha$, IL- $1 \beta$, and IL- 6 are known to increase the production of receptor activator of nuclear factor kappa-B ligand (RANKL) by pre-osteoblasts, thereby promoting osteoclastogenesis [21-23]. These cytokines bind to their respective receptors, which causes increased activation of p38 mitogen-activated protein kinase (MAPK), nuclear factor kappa-B (NF-KB), and c-Jun-N terminal kinase (JNK) pathways resulting in excessive bone loss and reducing BMD. Moreover, TNF- $\alpha$ inhibits the activation of R-spondin 2 (RSPO2), important for osteoblast maturation, causing decreased bone mass [24].

A role of IL-1beta has been proposed in IBD patients with a IL-1 $\beta-511 * 2$ polymorphism (carriers of allele 2 of the AvaI polymorphism), characterized by IL- $1 \beta$ hypersecretion, which induces a higher risk of diminished BMD than in healthy controls [25]. IL-17A, the defining cytokine of Th17 cells, has been shown to stimulate osteoclast formation [26]. However, in this study, osteoclast formation was predominantly from a non-classical blood monocyte precursor, while IL-17A did not affect the classical blood monocytes [27]. Moreover, Th17 cells express higher RANKL than other Th subsets suggesting they may indirectly promote osteoclastogenesis [28].

IL-12, a T cell mediator, is also an important inflammatory cytokine observed in IBD. It was reported that IL-12 induces apoptosis in bone marrow cells treated with TNF- $\alpha$ via an interaction between TNF- $\alpha$-induced Fas and IL-12-induced Fas ligand (FasL), and that, as a result, osteoclastogenesis is inhibited $[29,30]$.

Interestingly, the effects of IL-23 on bone appear to be pleotropic. Originally, it was suggested that IL-23 may act via IL-17 to induce osteoclastogenesis [31]. But later studies showed IL-23 to upregulate RANK expression on osteoclast precursor cells [32], and to promote osteoclastogenesis in coculture systems with osteoblasts [33]. Nevertheless, both suggested pathways lead to stimulation of bone resorption.

The effect of $\mathrm{T}$ cell-derived anti-inflammatory cytokines on bone cells is also extensively studied. Both interferon- $\gamma$ (IFN $\gamma$ ) and IL-4, the signature Th1 and Th2 cytokines, inhibit osteoclastogenesis $[34,35]$. IL-4 and the closely related IL-13 induced osteoprotogerin (OPG) expression in endothelial cells, which is an inhibitor of osteoclastic resorption [36]. In addition, inhibition of mRNA for RANK and nuclear factor of activated T cells 2 (NFAT2), a transcription factor, has also been noted. Consequently, IL-4 and IL-13 decrease the number of tartrate-resistant acid phosphatase-positive multinucleated cells and the mRNA expression of calcitonin receptor, tartrate-resistant acid phosphatase, and cathepsin $\mathrm{K}$ in mouse spleen cells and bone marrow macrophages treated with macrophage colony-stimulating factor and RANKL [37]. The effects of IL-4 and IL-13 have also been studied in osteoblasts, in which they stimulate production of IL-6 [38, 39]. Moreover, in an osteoblastic cell line (MG-63), IL-4 and IL13 inhibit mRNA expression of B1 and B2 kinin receptors induced by either IL- $1 \beta$ or TNF- $\alpha$, which is suggestive that these cytokines exert their anti-inflammatory effects, including impairment of bone resorption [40].

Although the predominantly negative effects of separate cytokines for bone are evident, in clinical situation, the patients have to deal with a cocktail of cytokines and inflammatory factors leaking into the circulation and thus eventually preparing the stage in bone tissue (see Fig. 1). Indeed, in Crohn's disease patients, osteoclastogenesis has been proven to be increased via $\mathrm{T}$ cell mediation [20]. In only a few studies, effects of a (complete) composition of inflammatory factors have been tested by using serum from Crohn's disease patients in an in vitro setting. In this balance-of-cytokine studies, it has been observed that bone formation measured by assaying calcium content and dry weight was decreased in intact bone explants when adding serum derived from Crohn's disease patients, even if these patients were in remission. With light microscopy of bone tissue, a discontinuous, uneven mineralized bone matrix and disorganized osteoblasts, characterized by altered morphology, were identified when treated with this mixture Crohn's disease patients' derived serum [41]. This effect was counteracted by blockade of IL-6. Even in children, osteoblast function and mineralization were affected by Crohn's disease patients'derived serum in vitro, suggesting a mechanism by which Crohn's disease may affect bone 
Fig. 1 Schematic representation of inflammatory changes and pathophysiology of IBDassociated osteoporosis. Treatment options and likely interference with pro-inflammatory changes underlying decreased bone health in IBD patients

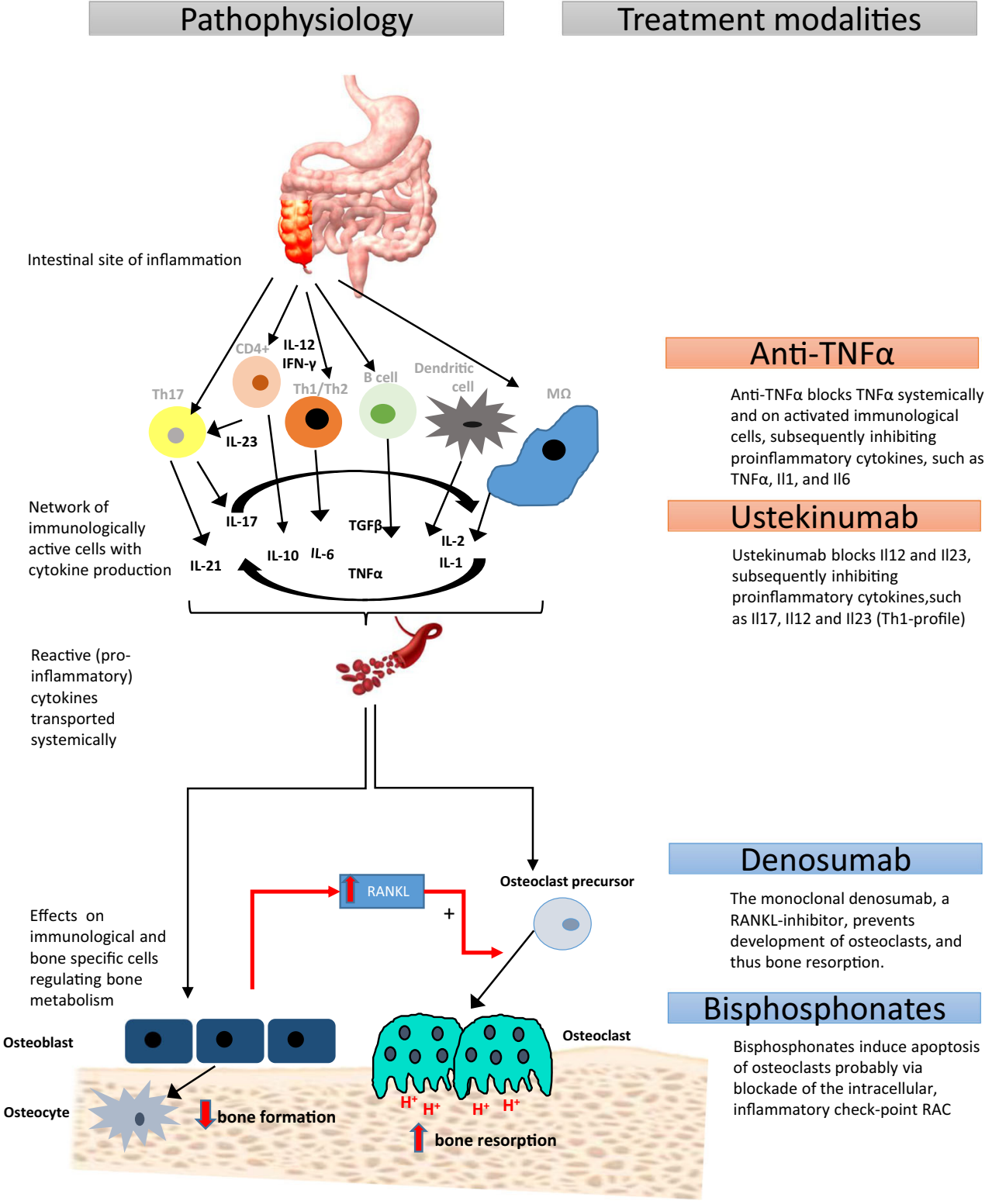

formation and, when occurring at young age, peak bone mass. In this latter study, IL-6-neutralizing antibody did not change the negative effect on osteoblasts [42]. Data from our own lab confirmed that serum from IBD patients in both active and quiescent state of disease contained an altered composition of inflammatory factors compared to healthy control serum. Bone cells showed reduced cell proliferation after exposure to IBD patient's serum [43]. To summarize, at the bone tissue level, cytokine profiles ascribed to the Th1 signature appear to promote osteoclastogenic bone resorption, whereas Th2signature profiles may counteract this. This balance between Th1-Th2 profiles may finally determine outcome on bone health. Balance-of-cytokine studies are warranted to further elucidate this concept.

Lately, gut-derived serotonin, produced by enterochromaffin cells of the duodenum, has attracted attention. It was shown in mice that high serotonin concentrations in blood were associated with osteoporosis, due to decreased osteoblast proliferation via activation of $5-\mathrm{HT}_{1 \mathrm{~B}}$ receptors on pre-osteoblasts. In line with this, both increased expression of the tryptophan hydroxylase inhibitor Lrp5 (low-density lipoprotein receptor-related protein 5) and decreased tryptophan hydroxylase 1 (Tph1) expression lead to decreased serotonin generation and secondarily to an increment of bone mass [44].

In colitis, elevated concentrations of serotonin have been demonstrated. As high, gut-derived serotonin concentrations have been associated with osteoporosis, colitis may contribute to osteoporosis in IBD patients. Conversely, inhibition of gutderived serotonin might become a treatment option for osteoporosis. These findings are now experimentally observed in animal studies, and corroboration of these findings in humans is awaited [45, 46]. 


\section{Vitamin D}

Recently, an immunomodulating effect of vitamin D on both the innate and the adaptive immune system has been established. In IBD patients, vitamin D might influence disease course [47]. Vitamin D levels in IBD patients are usually low, due to multiple reasons such as decreased intestinal absorption following surgery, deficient diet, and decreased sunlight exposure. At sufficient oral intake, calcium is predominantly absorbed via a non-saturable, paracellular diffusive pathway in the duodenum and proximal jejunum, regulated via the dynamics of the epithelial tight junctions. 1,25 (OH)2D3 (calcitriol) may enhance paracellular $\mathrm{Ca}^{2+}$ permeability. Vitamin D absorption is dependent upon its dissolution in micelles and occurs by simple passive diffusion and partly via the paraintestinal lymph drainage system [48-51]. In addition, sun exposure of the skin with ultraviolet B (UVB)-rich light induces vitamin $\mathrm{D}_{3}$ (cholecalciferol) generation from 7 dihydrocholesterol, a less efficient process with aging. With respect to bone, low levels of vitamin D are correlated with secondary hyperparathyroidism [52]. Secondary hyperparathyroidism is characterized by high bone turnover leading to low bone mass and increased fracture incidence. However, in a mouse model for UC, high vitamin $\mathrm{D}$ was shown to have adverse effects on bone health, likely because of the synergy with circulating pro-inflammatory mediators on a resorptive effect, leading to loss of BMD [53]. This phenomenon has not yet been confirmed in a clinical setting.

\section{Treatment considerations}

The ultimate clinical goal of treatment of an impaired bone health in IBD patients is prevention of bone fractures. Most data and studies regarding fracture prevention derive, however, from general osteoporosis or other (non-IBD) patient populations at risk for bone fractures. Overall, however, IBD patients seem to have higher risks than the general population [10], and identification of high-risk individuals in this IBD population is warranted. This may be done by assessment of calcium and vitamin D concentrations in IBD patients, at least at a yearly basis, and DXA measurement in all IBD patients with an increased risk for osteoporosis. Risk factors comprise a family history of osteoporosis, a low body mass index, smoking, chronic active IBD, and particularly corticosteroid therapy, especially when ongoing for more than 3 months. Genetic profiling is not yet well established. The occurrence of a fragility fracture necessitates additional DXA measurement.

Based on this risk profile, therapy to improve bone health and to prevent fragility fractures is recommended. When insufficient robust investigational data is available, clinical and pathophysiological reasoning becomes more important and relevant. This is the case in IBD patients with osteopenia, osteoporosis, or fragility fractures.

We would therefore like to propose an algorithm, based on the above-discussed variables contributing to impaired bone health in IBD patients, and focus on which treatment options may more specifically affect pathophysiology of bone health in IBD patients (see Figs. 1 and 2). The suggested treatment option may partly depend on epidemiological findings only. In addition, bone-specific treatment options will be briefly discussed.

\section{General factors}

Patients with IBD are at risk for several factors contributing to a decreased bone health. These include a low intake of calcium (with or without allegedly presence of lactose intolerance, or any allegedly "health-promoting" diet), low magnesium and potassium concentrations, sometimes associated with decreased overall oral intake or due to disturbed physiology of intestinal absorption in intestinal inflammation [48], decreased vitamin D concentrations, due to intestinal malabsorption, decreased nutritional intake, and decreased sunlight (UVB) exposure.

IBD patients with a high disease burden usually have various forms of malnutrition including a low body mass index on average $[54,55]$. A low body mass index in adults is commonly accompanied by osteopenia and decreased muscle strength [56], and in children it is associated with a low peak bone mass, which is probably also present due to inflammatory changes associated with IBD [57]. In IBD, low serum vitamin $\mathrm{D}$ concentration is common [58,59], but supplementation may be hampered by disturbed intestinal absorption and, seemingly at the best, stabilizes bone health [60, 61].

Decreased physical activity, also associated with less sun exposure, is highly prevalent in chronically diseased individuals, and, thus, in IBD patients. Life style advices, comprising physical exercise and sun exposure, and diet supplementation, easiest by a multicomponent supplement, may all contribute to an improved bone health, and is therefore recommended [50, 62]. Smoking is a risk factor for decreased bone health, although challenged in IBD patients [63], but as smoking is a no-go area in IBD itself, it should be abandoned anyhow. Similarly, excessive alcohol intake must be discouraged. Low body mass index and decreased fat-free body mass is common in IBD patients, which correlates with a decreased BMD [64]. Optimization of nutritional status, particularly in the pediatric and young IBD patients, may prevent fractures in the elderly. Low-impact exercise contributes to a better bone health in a similar way, contributing to an improved disease course in IBD, as well $[65,66]$. Overall, diet and life style measures may be reliably advocated in general, and, similarly, in IBD patients. 
Fig. 2 Suggested algorithm for diagnosis and treatment of IBDassociated decreased bone health

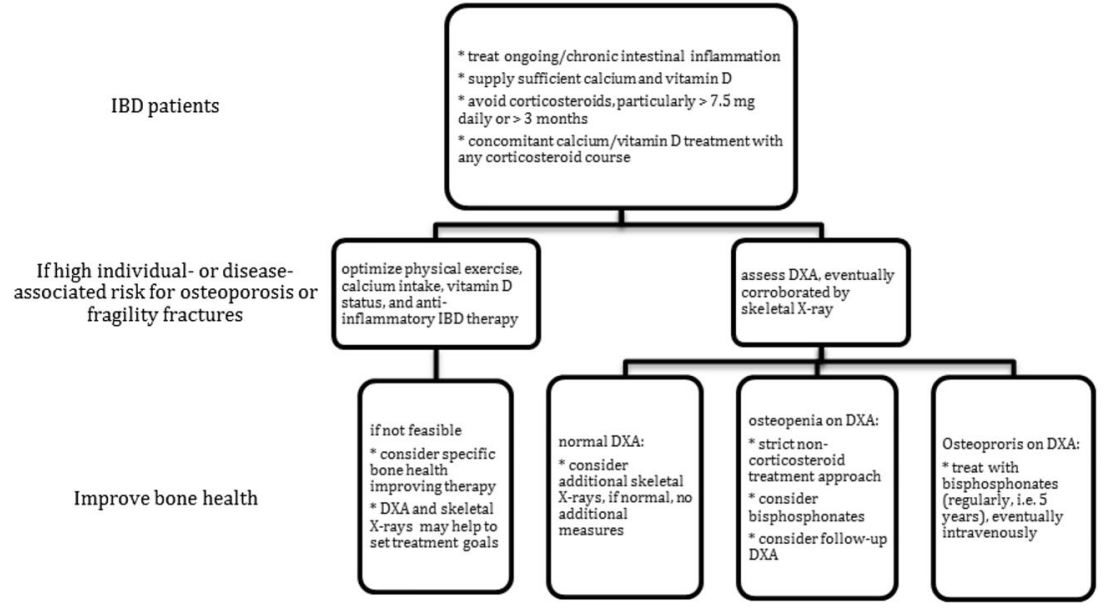

\section{IBD-related therapy}

Use of corticosteroids, a stimulator of osteoclastogenesis, particularly when long term and in higher dosages, decreases bone health and should therefore be avoided whenever possible. If prescribed or continued, one may apply the recommendations from the American College of Rheumatology on glucocorticoid-induced osteoporosis. In their guideline, this College states that limited evidence regarding the balance between benefit and harm of interventions in corticosteroid users is available. Treatment with calcium and vitamin D only is advocated in patients with low fragility fracture risk, while addition of a (intravenous) bisphosphonate may be considered in adults at moderate-to-high fracture risk. Switch to alternative bone protecting therapy may be considered when a contraindication for bisphosphonate use is present [67].

Use of anti-TNF therapy, on the other hand, may increase bone density, whether by direct beneficial impact on bone physiology or by decreasing disadvantageous inflammatory changes on bone health, although still under debate [68-71]. Commonly used IBD medication, belonging to other therapeutic classes, such as mesalazines, immunosuppressants, and newly developed biologics or small molecules, like vedolizumab and tofacitinib, have not extensively been studied with regard to bone physiology. The same holds true for the IL-12/IL-23 inhibitor ustekinumab. Taking these findings into account, one may identify an ideal therapy strategy in individual patient cases; however, it is primarily the treatment choice necessitated by the course of IBD which determines the final therapy class. If corticosteroids are being prescribed, concomitant use of calcium and vitamin D supplementation may be advised as routine, based on pathophysiological considerations, whereas robust trials are lacking, partly due to huge challenges to design a statistically well-powered trial $[61,67]$.

\section{IBD-specific factors}

IBD patients seem at an increased risk for sex hormone deficiency, and when identified may be supplemented, also to improve bone health [65]. Effects of intestinal inflammation are discussed below.

\section{Gastrointestinal damage in IBD}

Functional and surgery-induced digestive disorders form part of the clinical spectrum of IBD, in addition to potentially increased intestinal leakage [50]. In general, supplemental multivitamin preparations seem therefore beneficial, although not formally evidenced by trials. Intestinal insufficiency (short bowel syndrome) is less frequently observed by the advent of new potent drugs and surgical techniques.

Extent of resected small-bowel segments have been related to vitamin $\mathrm{D}$ deficiency [72], whereas terminal ileal resection interferes with vitamin $\mathrm{B}_{12}$ deficiency and a decreased bile acid pool, associated with lower levels of most fat-soluble vitamins. Identification and restoration of any nutritional (point) deficiency may be advocated.

\section{Inflammatory processes underlying IBD}

As described above, many systemic inflammatory mediators, as generated by the inflammatory process underlying IBD, influence bone metabolism adversely. Specific therapy against inflammation, such as anti-TNF therapy, is therefore believed to induce beneficial effects on bone health. Similarly, the inhibition of the proinflammatory cytokines IL-12 and IL-23, by means of ustekinumab (Stelara $\left.{ }^{\circledR}\right)$, may depress RANKL, and via this pathway may be bone health protective. This, however, has not yet been substantiated in clinical studies. Strict therapy of IBD itself may also improve bone density [73], corroborating the concept that systemic inflammation itself, as in IBD, is detrimental for bone health. In addition, anti- 
inflammatory effects of vitamin D may be helpful to improve bone health like cutting as a two-sided sword [74].

\section{Bone-specific therapy}

\section{Calcium and vitamin D}

Supplemental use of calcium plus vitamin D has been supported by circumstantial evidence [75, 76]. This should be routinely prescribed concurrent with corticosteroid therapy for IBD, although firm evidence is lacking [67]. We propose to use high dosages ( $1 \mathrm{~g}$ calcium o.d. and vitamin D $800 \mathrm{IU}$ o.d.) in order to ensure adequate bio-availability. Hormone replacement and sodium fluoride therapy have been abandoned for these purposes in IBD patients.

\section{Bisphosphonates}

Bisphosphonate use (most commonly risedronate, but virtually all other components have been studied in one or more studies as well) has been analyzed in IBD patients in several studies with relatively large heterogeneity in trial design, study population, and control groups. In two, recent, metaanalyses, overall use of bisphosphonates is believed to be beneficial $[61,77]$. Mean increment of spine BMD values was calculated to be 0.41 (95\% CI 0.18-0.64), and on total hip scores, this amounted to 0.29 (95\% CI 0.11-0.46) with acceptable heterogeneity between trials [77]. The odds ratio of incident total new fractures was 0.30 (95\% CI 0.13-0.69); adverse events were comparable between bisphosphonate users and controls [77]. Given the potential impaired absorption of bisphosphonates in patients with intestinal disease or inflammation, with or without a prior history of surgery for IBD, intravenous bisphosphonates may be an appealing route of administration.

Several questions regarding optimal bone-specific therapy remain. It is yet not clear whether treatment advices in geriatrics/general osteoporosis may also be applied to the relatively young IBD patients with impaired bone health. Treating IBD-related osteoporosis, only following an established diagnosis by DXA, may be putting the cart before the horse. In guidelines, it is advocated not to screen all IBD patients, but only those with additional risk for osteoporosis, based on epidemiological data. Still, osteoporosis and bone fractures remain an important clinical problem. Theoretically, the risk for fractures may be diminished by preserving peak bone mass of young people, i.e. by aggressively or promptly treating osteopenia early on, especially in young patients with additional osteoporosis risk factors. Bisphosphonates may be helpful in these patients to improve bone health [78].

In addition, as systemic inflammation is an important driver of premature, IBD-associated impaired bone health, more efforts may be undertaken to reduce inflammatory burden, to increase peak bone mass or reduce unnecessary loss of bone mass when possible and to timely treat quantified decreased bone mass in order to avoid fractures later on [73]. Whether therapeutics for improving bone health, like bisphosphonates, preclude recovery of presenile loss of bone mass, thus counteract the effects of treatment of inflammatory burden such as in IBD [73], or whether osteoblastic activity such as by supplementation of calcium or vitamin D may be hampered when prescribing bisphosphonates or denosumab remains to be answered. Therefore, timing of (bone) treatment in IBD patients needs to be addressed in additional trials.

\section{Denosumab and other new bone health-improving agents}

A more recent therapeutic agent for treatment of osteoporosis is denosumab, a RANKL inhibitor. In IBD patients, this compound has not yet been scrutinized. This may be due to a theoretical disadvantage. RANKL inhibition by denosumab might affect NF- $\mathrm{KB}$ function which is pivotal in inflammation, and thus in chronic intestinal inflammation such as IBD. Interestingly, the use of denosumab seems neither related to a higher risk for inflammatory activity (relapse of IBD), nor for an increased risk for infectious diseases [79]. This has been subject of study in rheumatoid arthritis but not in IBD [80], and effects on bone formation more than on bone resorption have been proposed when observing elevated concentrations of bone-specific alkaline phosphatase [81]. In addition, denosumab use seems to be associated with a rebound effect following discontinuation of therapy which may be considered to be a major flaw when using this drug in the relative young IBD population [82]. Parathormone has anabolic effects on bone metabolism, like the recombinant hormone teriparatide. This may be an interesting medication in low peak bone mass as is found in IBD patients. However, it has been studied in corticosteroid-associated osteoporosis, but not in IBD patients as such [83].

Overall, if opting for drugs like these, robust scientific evidence is lacking and these options should be restricted to individuals with peculiar clinical circumstances, by preference in centers of excellence.

In conclusion, assessment of impaired bone health in IBD patients relies on DXA in clinical practice, with sometimes additional radiographs of the spine, whether primarily for suspected osteoporosis or secondarily as an incidental finding on abdominal CT scan (for IBD purposes). Assessment of the intestinal inflammatory burden and bone-influencing drugs like corticosteroids or TNF inhibitors form part of determination of bone health risk. Advice to introduce general bone health-promoting procedures and strict control of disease activity contribute to optimal bone health. When treating impaired bone health in IBD patients, focus should be on general 
advices such as calcium supplementation, sufficient vitamin D use, and life style and diet measures. Medications to improve bone health ideally should be chosen based on pathophysiological reasoning corroborated by relatively sparse specific trials in the population at risk. Timing of drugs remains a subject of study, as well as the sequence in which drugs, and in which drug classes, may be advised. More recently introduced agents are insufficiently documented for regular use in IBD patients with bone health at risk.

\section{Compliance with ethical standards}

\section{Conflicts of interest None.}

Open Access This article is distributed under the terms of the Creative Commons Attribution-NonCommercial 4.0 International License (http:// creativecommons.org/licenses/by-nc/4.0/), which permits any noncommercial use, distribution, and reproduction in any medium, provided you give appropriate credit to the original author(s) and the source, provide a link to the Creative Commons license, and indicate if changes were made.

\section{References}

1. Ananthakrishnan AN (2015) Epidemiology and risk factors for IBD. Nat Rev Gastroenterol Hepatol 12:205-217

2. van den Heuvel TRA, Jeuring SFG, Zeegers MP, van Dongen D, Wolters A, Masclee AAM, Hameeteman WH, Romberg-Camps MJL, Oostenbrug LE, Pierik MJ, Jonkers DM (2017) A 20-year temporal change analysis in incidence, presenting phenotype and mortality, in the Dutch IBDSL cohort-can diagnostic factors explain the increase in IBD incidence? J Crohns Colitis 11:1169-1179

3. Romberg-Camps MJ, Dagnelie PC, Kester AD, Hesselink-van de Kruijs M, Cilissen M, Engels LG, van Deursen C, Hameeteman WH, Wolters FL, Russel MG, Stockbrügger RW (2009) Influence of phenotype at diagnosis and of other potential prognostic factors on the course of inflammatory bowel disease. Am J Gastroenterol 104:371-383

4. Bernstein CN, Blanchard JF, Leslie W, Wajda A, Yu BN (2000) The incidence of fracture among patients with inflammatory bowel disease. A population-based cohort study. Ann Intern Med 133:795799

5. Vestergaard P, Mosekilde L (2002) Fracture risk in patients with celiac disease, Crohn's disease, and ulcerative colitis: a nationwide follow-up study of 16,416 patients in Denmark. Am J Epidemiol 156:1-10

6. van Staa TP, Cooper C, Brusse LS, Leufkens H, Javaid MK, Arden NK (2003) Inflammatory bowel disease and the risk of fracture. Gastroenterology 125:1591-1597

7. Card T, West J, Hubbard R, Logan RF (2004) Hip fractures in patients with inflammatory bowel disease and their relationship to corticosteroid use: a population based cohort study. Gut 53:251255

8. Kappelman MD, Galanko JA, Porter CQ, Sandler RS (2011) Risk of diagnosed fractures in children with inflammatory bowel diseases. Inflamm Bowel Dis 17:1125-1130

9. Tsai MS, Lin CL, Tu YK, Lee PH, Kao CH (2015) Risks and predictors of osteoporosis in patients with inflammatory bowel diseases in an Asian population: a nationwide population-based cohort study. Int J Clin Pract 69:235-241

10. Szafors P, Che H, Barnetche T, Morel J, Gaujoux-Viala C, Combe B, Lukas C (2018) Risk of fracture and low bone mineral density in adults with inflammatory bowel diseases. A systematic literature review with meta-analysis. Osteoporos Int

11. Komaki Y, Komaki F, Micic D, Ido A, Sakuraba A (2018) Risk of fractures in inflammatory bowel diseases: a systematic review and meta-analysis. J Clin Gastroenterol

12. Ferrari S, Bianchi ML, Eisman JA, Foldes AJ, Adami S, Wahl DA, Stepan JJ, de Vernejoul MC, Kaufman JM, Pathophysiology IOFCoSAWGoO (2012) Osteoporosis in young adults: pathophysiology, diagnosis, and management. Osteoporos Int 23:2735-2748

13. Schulte C, Dignass AU, Mann K, Goebell H (1998) Reduced bone mineral density and unbalanced bone metabolism in patients with inflammatory bowel disease. Inflamm Bowel Dis 4:268-275

14. Ott C, Scholmerich J (2013) Extraintestinal manifestations and complications in IBD. Nat Rev Gastroenterol Hepatol 10:585-595

15. Peyrin-Biroulet L, Ferrante M, Magro F, Campbell S, Franchimont D, Fidder H, Strid H, Ardizzone S, Veereman-Wauters G, Chevaux JB, Allez M, Danese S, Sturm A, Scientific Committee of the European Crohn's and Colitis Organization (2011) Results from the 2nd Scientific Workshop of the ECCO. I: Impact of mucosal healing on the course of inflammatory bowel disease J Crohns Colitis 5:477-483

16. Vazquez MA, Lopez E, Montoya MJ, Giner M, Perez-Temprano R, Perez-Cano R (2012) Vertebral fractures in patients with inflammatory bowel disease compared with a healthy population: a prospective case-control study. BMC Gastroenterol 12:47

17. Li C, Huang Q, Yang R, Dai Y, Zeng Y, Tao L, Li X, Zeng J, Wang Q (2019) Gut microbiota composition and bone mineral lossepidemiologic evidence from individuals in Wuhan, China. Osteoporos Int

18. Chetcuti Zammit S, Ellul P, Girardin G, Valpiani D, Nielsen KR, Olsen J, Goldis A, Lazar D, Shonová O, Nováková M, Sebastian S, Whitehead E, Carmona A, Martinez-Cadilla J, Dahlerup JF, Kievit ALH, Thorsgaard N, Katsanos KH, Christodoulou DK, Magro F, Salupere R, Pedersen N, Kjeldsen J, Carlsen K, Ioannis K, Bergemalm D, Halfvarson J, Duricova D, Bortlik M, Collin P, Oksanen P, Kiudelis G, Kupcinskas L, Kudsk K, Andersen V, O, Morain C, Bailey Y, Doron S, Shmuel O, Almer S, Arebi N, Misra R, Čuković-Čavka S, Brinar M, Munkholm P, Vegh Z, Burisch J (2018) Vitamin D deficiency in a European inflammatory bowel disease inception cohort: an Epi-IBD study. Eur J Gastroenterol Hepatol 30:1297-1303

19. Briot K, Roux C (2015) Inflammation, bone loss and fracture risk in spondyloarthritis. RMD Open 1:e000052

20. Oostlander AE, Everts V, Schoenmaker T, Bravenboer N, van Vliet SJ, van Bodegraven AA, Lips P, de Vries TJ (2012) T cell-mediated increased osteoclast formation from peripheral blood as a mechanism for Crohn's disease-associated bone loss. J Cell Biochem 113: 260-268

21. Reinecker HC, Steffen M, Witthoeft T, Pflueger I, Schreiber S, MacDermott RP, Raedler A (1993) Enhanced secretion of tumour necrosis factor-alpha, IL-6, and IL-1 beta by isolated lamina propria mononuclear cells from patients with ulcerative colitis and Crohn's disease. Clin Exp Immunol 94:174-181

22. Neurath MF, Finotto S (2011) IL-6 signaling in autoimmunity, chronic inflammation and inflammation-associated cancer. Cytokine Growth Factor Rev 22:83-89

23. Tilg H, Moschen AR, Kaser A, Pines A, Dotan I (2008) Gut, inflammation and osteoporosis: basic and clinical concepts. Gut 57: 684-694

24. Agrawal M, Arora S, Li J, Rahmani R, Sun L, Steinlauf AF, Mechanick JI, Zaidi M (2011) Bone, inflammation, and inflammatory bowel disease. Curr Osteoporos Rep 9:251-257 
25. Nemetz A, Toth M, Garcia-Gonzalez MA, Zagoni T, Feher J, Pena AS, Tulassay Z (2001) Allelic variation at the interleukin 1beta gene is associated with decreased bone mass in patients with inflammatory bowel diseases. Gut 49:644-649

26. Tucci M, Stucci S, Savonarola A, Ciavarella S, Cafforio P, Dammacco F, Silvestris F (2013) Immature dendritic cells in multiple myeloma are prone to osteoclast-like differentiation through interleukin-17A stimulation. Br J Haematol 161:821-831

27. Sprangers S, Schoenmaker T, Cao Y, Everts V, de Vries TJ (2016) Different blood-borne human osteoclast precursors respond in distinct ways to IL-17A. J Cell Physiol 231:1249-1260

28. Ganesan R, Rasool M (2017) Interleukin 17 regulates SHP-2 and IL-17RA/STAT-3 dependent Cyr61, IL-23 and GM-CSF expression and RANKL mediated osteoclastogenesis by fibroblast-like synoviocytes in rheumatoid arthritis. Mol Immunol 91:134-144

29. Kitaura H, Nagata N, Fujimura Y, Hotokezaka H, Yoshida N, Nakayama K (2002) Effect of IL-12 on TNF-alpha-mediated osteoclast formation in bone marrow cells: apoptosis mediated by Fas/ Fas ligand interaction. J Immunol 169:4732-4738

30. Yoshimatsu M, Kitaura H, Fujimura Y, Eguchi T, Kohara H, Morita Y, Yoshida N (2009) IL-12 inhibits TNF-alpha induced osteoclastogenesis via a $\mathrm{T}$ cell-independent mechanism in vivo. Bone 45: $1010-1016$

31. Yago T, Nanke Y, Kawamoto M, Furuya T, Kobashigawa T, Kamatani N, Kotake S (2007) IL-23 induces human osteoclastogenesis via IL-17 in vitro, and anti-IL-23 antibody attenuates collagen-induced arthritis in rats. Arthritis Res Ther 9:R96

32. Chen L, Wei XQ, Evans B, Jiang W, Aeschlimann D (2008) IL-23 promotes osteoclast formation by up-regulation of receptor activator of NF-kappaB (RANK) expression in myeloid precursor cells. Eur J Immunol 38:2845-2854

33. Kang YK, Zhang MC (2014) IL-23 promotes osteoclastogenesis in osteoblast-osteoclast co-culture system. Genet Mol Res 13:46734679

34. Kotake S, Nanke Y, Mogi M, Kawamoto M, Furuya T, Yago T, Kobashigawa T, Togari A, Kamatani N (2005) IFN-gammaproducing human $\mathrm{T}$ cells directly induce osteoclastogenesis from human monocytes via the expression of RANKL. Eur J Immunol 35:3353-3363

35. Mirosavljevic D, Quinn JM, Elliott J, Horwood NJ, Martin TJ, Gillespie MT (2003) T-cells mediate an inhibitory effect of interleukin-4 on osteoclastogenesis. J Bone Miner Res 18:984-993

36. Stein NC, Kreutzmann C, Zimmermann SP, Niebergall U, Hellmeyer L, Goettsch C, Schoppet M, Hofbauer LC (2008) Interleukin-4 and interleukin-13 stimulate the osteoclast inhibitor osteoprotegerin by human endothelial cells through the STAT6 pathway. J Bone Miner Res 23:750-758

37. Palmqvist P, Lundberg P, Persson E, Johansson A, Lundgren I, Lie A, Conaway HH, Lerner UH (2006) Inhibition of hormone and cytokine-stimulated osteoclastogenesis and bone resorption by interleukin-4 and interleukin-13 is associated with increased osteoprotegerin and decreased RANKL and RANK in a STAT6dependent pathway. J Biol Chem 281:2414-2429

38. Frost A, Jonsson KB, Brandstrom $\mathrm{H}$, Ljunghall S, Nilsson $\mathrm{O}$, Ljunggren O (2001) Interleukin (IL)-13 and IL-4 inhibit proliferation and stimulate IL-6 formation in human osteoblasts: evidence for involvement of receptor subunits IL-13R, IL-13Ralpha, and IL4Ralpha. Bone 28:268-274

39. Silfversward CJ, Frost A, Brandstrom H, Nilsson O, Ljunggren O (2004) Interleukin-4 and interleukin-13 potentiate interleukin-1 induced secretion of interleukin-6 in human osteoblast-like cells. J Orthop Res 22:1058-1062

40. Souza PP, Brechter AB, Reis RI, Costa CA, Lundberg P, Lerner UH (2013) IL-4 and IL-13 inhibit IL-1beta and TNF-alpha induced kinin B1 and B2 receptors through a STAT6-dependent mechanism. Br J Pharmacol 169:400-412
41. Sylvester FA, Wyzga N, Hyams JS, Gronowicz GA (2002) Effect of Crohn's disease on bone metabolism in vitro: a role for interleukin6. J Bone Miner Res 17:695-702

42. Varghese S, Wyzga N, Griffiths AM, Sylvester FA (2002) Effects of serum from children with newly diagnosed Crohn disease on primary cultures of rat osteoblasts. J Pediatr Gastroenterol Nutr 35: 641-648

43. Oostlander AB, N; Lems, WF; Klein-Nulend, J; Schulten, EA; van Bodegraven, AA; Lips, P. (2008) Effect of proinflammatory cytokines and serum of Crohn's disease patients on primary human osteoblast proliferation. CALCIFIED TISSUE INTERNATIONAL, pp S113-S113

44. Karsenty G, Gershon MD (2011) The importance of the gastrointestinal tract in the control of bone mass accrual. Gastroenterology 141:439-442

45. Yadav VK, Balaji S, Suresh PS, Liu XS, Lu X, Li Z, Guo XE, Mann JJ, Balapure AK, Gershon MD, Medhamurthy R, Vidal M, Karsenty G, Ducy P (2010) Pharmacological inhibition of gutderived serotonin synthesis is a potential bone anabolic treatment for osteoporosis. Nat Med 16:308-312

46. Lavoie B, Roberts JA, Haag MM, Spohn SN, Margolis KG, Sharkey KA, Lian JB, Mawe GM (2019) Gut-derived serotonin contributes to bone deficits in colitis. Pharmacol Res 140:75-84

47. Nielsen OH, Rejnmark L, Moss AC (2018) Role of vitamin D in the natural history of inflammatory bowel disease. J Crohns Colitis 12 : $742-752$

48. Kiela PR, Ghishan FK (2016) Physiology of intestinal absorption and secretion. Best Pract Res Clin Gastroenterol 30:145-159

49. Krawitt EL, Beeken WL, Janney CD (1976) Calcium absorption in Crohn's disease. Gastroenterology 71:251-254

50. Ghishan FK, Kiela PR (2017) Vitamins and minerals in inflammatory bowel disease. Gastroenterol Clin N Am 46:797-808

51. Sitrin MD, Pollack KL, Bolt MJ (1985) Intestinal absorption of 1, 25-dihydroxyvitamin D3 in the rat. Am J Phys 248:G718-G725

52. Kuchuk NO, van Schoor NM, Pluijm SM, Chines A, Lips P (2009) Vitamin D status, parathyroid function, bone turnover, and BMD in postmenopausal women with osteoporosis: global perspective. J Bone Miner Res 24:693-701

53. Larmonier CB, McFadden RM, Hill FM, Schreiner R, Ramalingam R, Besselsen DG, Ghishan FK, Kiela PR (2013) High vitamin D3 diet administered during active colitis negatively affects bone metabolism in an adoptive T cell transfer model. Am J Physiol Gastrointest Liver Physiol 305:G35-G46

54. Geerling BJ, Badart-Smook A, Stockbrugger RW, Brummer RJ (2000) Comprehensive nutritional status in recently diagnosed patients with inflammatory bowel disease compared with population controls. Eur J Clin Nutr 54:514-521

55. Scaldaferri F, Pizzoferrato M, Lopetuso LR et al (2017) Nutrition and IBD: malnutrition and/or sarcopenia? A practical guide. Gastroenterol Res Pract 2017:8646495

56. Bryant RV, Ooi S, Schultz CG, Goess C, Grafton R, Hughes J, Lim A, Bartholomeusz FD, Andrews JM (2015) Low muscle mass and sarcopenia: common and predictive of osteopenia in inflammatory bowel disease. Aliment Pharmacol Ther 41:895-906

57. Laakso S, Valta H, Verkasalo M, Toiviainen-Salo S, Makitie O (2014) Compromised peak bone mass in patients with inflammatory bowel disease-a prospective study. J Pediatr 164:1436-1443 e1431

58. Suibhne TN, Cox G, Healy M, O’Morain C, O’Sullivan M (2012) Vitamin D deficiency in Crohn's disease: prevalence, risk factors and supplement use in an outpatient setting. J Crohns Colitis 6:182188

59. Miller HL, Farraye FA, Coukos J, Howard LA, Holick MF, Stucchi AF, Becker JM (2013) Vitamin D deficiency and insufficiency are common in ulcerative colitis patients after ileal pouch-anal anastomosis. Inflamm Bowel Dis 19:E25-E26 
60. Vogelsang H, Ferenci P, Resch H, Kiss A, Gangl A (1995) Prevention of bone mineral loss in patients with Crohn's disease by long-term oral vitamin D supplementation. Eur J Gastroenterol Hepatol 7:609-614

61. Melek J, Sakuraba A (2014) Efficacy and safety of medical therapy for low bone mineral density in patients with inflammatory bowel disease: a meta-analysis and systematic review. Clin Gastroenterol Hepatol 12:32-44 e35

62. Robinson RJ, Krzywicki T, Almond L, al-Azzawi F, Abrams K, Iqbal SJ, Mayberry JF (1998) Effect of a low-impact exercise program on bone mineral density in Crohn's disease: a randomized controlled trial. Gastroenterology 115:36-41

63. Schulte C, Dignass AU, Mann K, Goebell H (1999) Bone loss in patients with inflammatory bowel disease is less than expected: a follow-up study. Scand J Gastroenterol 34:696-702

64. Targownik LE, Bernstein CN, Leslie WD (2014) Risk factors and management of osteoporosis in inflammatory bowel disease. Curr Opin Gastroenterol 30:168-174

65. Robinson RJ, Iqbal SJ, Al-Azzawi F, Abrams K, Mayberry JF (1998) Sex hormone status and bone metabolism in men with Crohn's disease. Aliment Pharmacol Ther 12:21-25

66. Tew GA, Jones K, Mikocka-Walus A (2016) Physical activity habits, limitations, and predictors in people with inflammatory bowel disease: a large cross-sectional online survey. Inflamm Bowel Dis 22:2933-2942

67. Buckley L, Guyatt G, Fink HA et al (2017) 2017 American College of Rheumatology Guideline for the prevention and treatment of glucocorticoid-induced osteoporosis. Arthritis Rheumatol 69: 1521-1537

68. Miheller P, Muzes G, Zagoni T, Toth M, Racz K, Tulassay Z (2006) Infliximab therapy improves the bone metabolism in fistulizing Crohn's disease. Dig Dis 24:201-206

69. Veerappan SG, O'Morain CA, Daly JS, Ryan BM (2011) Review article: the effects of antitumour necrosis factor-alpha on bone metabolism in inflammatory bowel disease. Aliment Pharmacol Ther 33:1261-1272

70. Sugimoto K, Ikeya K, Iida T et al (2016) An increased serum Nterminal telopeptide of type I collagen, a biochemical marker of increased bone resorption, is associated with infliximab therapy in patients with Crohn's disease. Dig Dis Sci 61:99-106

71. Krajcovicova A, Hlavaty T, Killinger $Z$ et al (2014) Combination therapy with an immunomodulator and anti-TNFalpha agent improves bone mineral density in IBD patients. J Crohns Colitis 8: 1693-1701

72. Leichtmann GA, Bengoa JM, Bolt MJ, Sitrin MD (1991) Intestinal absorption of cholecalciferol and 25-hydroxycholecalciferol in patients with both Crohn's disease and intestinal resection. Am J Clin Nutr 54:548-552
73. Bakker SF, Dik VK, Witte BI, Lips P, Roos JC, Van Bodegraven AA (2013) Increase in bone mineral density in strictly treated Crohn's disease patients with concomitant calcium and vitamin D supplementation. J Crohns Colitis 7:377-384

74. Raftery T, O'Morain CA, O’Sullivan M (2012) Vitamin D: new roles and therapeutic potential in inflammatory bowel disease. Curr Drug Metab 13:1294-1302

75. Bernstein CN, Seeger LL, Anton PA, Artinian L, Geffrey S, Goodman W, Belin TR, Shanahan F (1996) A randomized, placebo-controlled trial of calcium supplementation for decreased bone density in corticosteroid-using patients with inflammatory bowel disease: a pilot study. Aliment Pharmacol Ther 10:777-786

76. Benchimol EI, Ward LM, Gallagher JC, Rauch F, Barrowman N, Warren J, Beedle S, Mack DR (2007) Effect of calcium and vitamin D supplementation on bone mineral density in children with inflammatory bowel disease. J Pediatr Gastroenterol Nutr 45:538-545

77. Hu Y, Chen X, Chen X, Zhang S, Jiang T, Chang J, Gao Y (2017) Bone loss prevention of bisphosphonates in patients with inflammatory bowel disease: a systematic review and meta-analysis. Can J Gastroenterol Hepatol 2017:2736547

78. van Bodegraven AA, Bravenboer N, Witte BI, Dijkstra G, van der Woude C, Stokkers PC, Russel MG, Oldenburg B, Pierik M, Roos JC, van Hogezand R, Dik VK, Oostlander AE, Netelenbos JC, van de Langerijt L, Hommes DW, Lips P, Dutch Initiative on Crohn and Colitis (ICC) (2014) Treatment of bone loss in osteopenic patients with Crohn's disease: a double-blind, randomised trial of oral risedronate $35 \mathrm{mg}$ once weekly or placebo, concomitant with calcium and vitamin D supplementation. Gut 63:1424-1430

79. Ferrari-Lacraz S, Ferrari S (2011) Do RANKL inhibitors (denosumab) affect inflammation and immunity? Osteoporos Int 22:435-446

80. Dubrovsky AM, Lim MJ, Lane NE (2018) Osteoporosis in rheumatic diseases: anti-rheumatic drugs and the skeleton. Calcif Tissue Int 102:607-618

81. Kinoshita H, Miyakoshi N, Kashiwagura T, Kasukawa Y, Sugimura Y, Shimada Y (2017) Comparison of the efficacy of denosumab and bisphosphonates for treating secondary osteoporosis in patients with rheumatoid arthritis. Mod Rheumatol 27:582-586

82. McClung MR, Wagman RB, Miller PD, Wang A, Lewiecki EM (2017) Observations following discontinuation of long-term denosumab therapy. Osteoporos Int 28:1723-1732

83. Lane NE, Sanchez S, Modin GW, Genant HK, Pierini E, Arnaud CD (1998) Parathyroid hormone treatment can reverse corticosteroid-induced osteoporosis. Results of a randomized controlled clinical trial. J Clin Invest 102:1627-1633

Publisher's note Springer Nature remains neutral with regard to jurisdictional claims in published maps and institutional affiliations. 